\title{
INFLUENCE OF THE REMAINING WATER LAYER ON THE COOLING OF MOVING STEEL SURFACES
}

\author{
${ }^{1}$ Ondřej RESL, ${ }^{1}$ Michal POHANKA \\ ${ }^{1}$ Brno University of Technology, Faculty of Mechanical Engineering, Brno, Czech Republic, EU, \\ ondrej.resl@vut.cz
}

https://doi.org/10.37904/metal.2021.4101

\begin{abstract}
Steel is an integral part of today's life. To obtain the desired mechanical properties of hot rolled steel plates or strips, it is necessary to predict and control the cooling process. Cooling of a hot rolled strip on a run-out table or in a continuous annealing line is commonly realized by laminar and spray cooling, and involves a large amount of water, which impinges on the hot surface of the steel. Water is accumulated on the upper surface, which means the jets do not have a direct impact on the steel surface and the cooling intensity is changed. The cooling process is also affected by the remaining water layer that remains on the surface after cooling. This thin layer occurs both on the upper and the bottom surface, and also for light sprays. The remaining water can significantly influence the final temperature of the steel strip if the target temperature is below $500{ }^{\circ} \mathrm{C}$. In this article, the effect of remaining water on cooling is experimentally investigated. A full cone spray nozzle is used for the measurements and the cooling in different areas (under the nozzle, outside the nozzle spray) is studied.
\end{abstract}

Keywords: Steel, remaining water, cooling, heat transfer coefficient

\section{INTRODUCTION}

Steel is a basic material in the machinery and construction industries, but it is also used for example in healthcare or in everyday life. Steel is processed by hot rolling, cold rolling, quenching or other methods into the required products. Hot rolling is one of the most common ways of processing steel. The output of hot rolling is semi-finished products or final products like steel sheets, plates, wires, rails, etc. After the steel leaves the last rolling mill, it is cooled to the required final temperature on a run-out table (ROT). To achieve quality steel products with the desired mechanical and physical properties while keeping costs low, the cooling must be controlled. Achieving the appropriate cooling settings is a complicated process, because the cooling is influenced by many parameters, such as nozzle type, water flow rate, water temperature, surface temperature of the steel, velocity of the steel strip [1-4], surface roughness, presence of oxide, and accumulated and remaining water [5-9]. Many researchers have already worked on improving the cooling process, but there are still problems, such as low cooling efficiency, poor cooling uniformity and in particular reaching the exact final temperature when the target temperature is below $500^{\circ} \mathrm{C}$. [9,10].

The cooling on the ROT (or in the continuous annealing line) is connected with the large amount of water that impinges on the hot surface of the steel strip. This leads to the accumulation of water on the upper surface of the steel strip in the cooling section. The accumulated water stops jets having a direct impact on the steel surface, and also causes overcooling of edges and influences the cooling intensity [11]. The situation where the single circular water jet does not impinge on the steel surface directly but instead impinges on a surface covered with water was investigated by Fujimoto et al. [12]. Cho et al. [13] studied the cooling on the ROT and they developed an equation to predict the height of accumulated water from the water flow rate, nozzle spacing, and strip width. 
Cooling is also affected by the remaining water layer that remains on the surface after cooling. In contrast to accumulated water, the remaining water layer occurs not only on the upper surface, but also on the bottom surface (Figure 1). This thin layer can also be observed for light spray. In our previous research [9] (where the effect of the remaining water layer on the final temperature of the steel strip was investigated based on numerical simulations with experimentally obtained boundary conditions) it was found that the remaining water layer has a big influence on the final temperature when the target temperature is below $500^{\circ} \mathrm{C}$. These findings were also confirmed by a steel producer.

Almost no studies deal with the problematics of remaining water and therefore there is a lack of information about the influence of remaining water on cooling. In this study, the effect of remaining water on cooling is experimentally investigated.

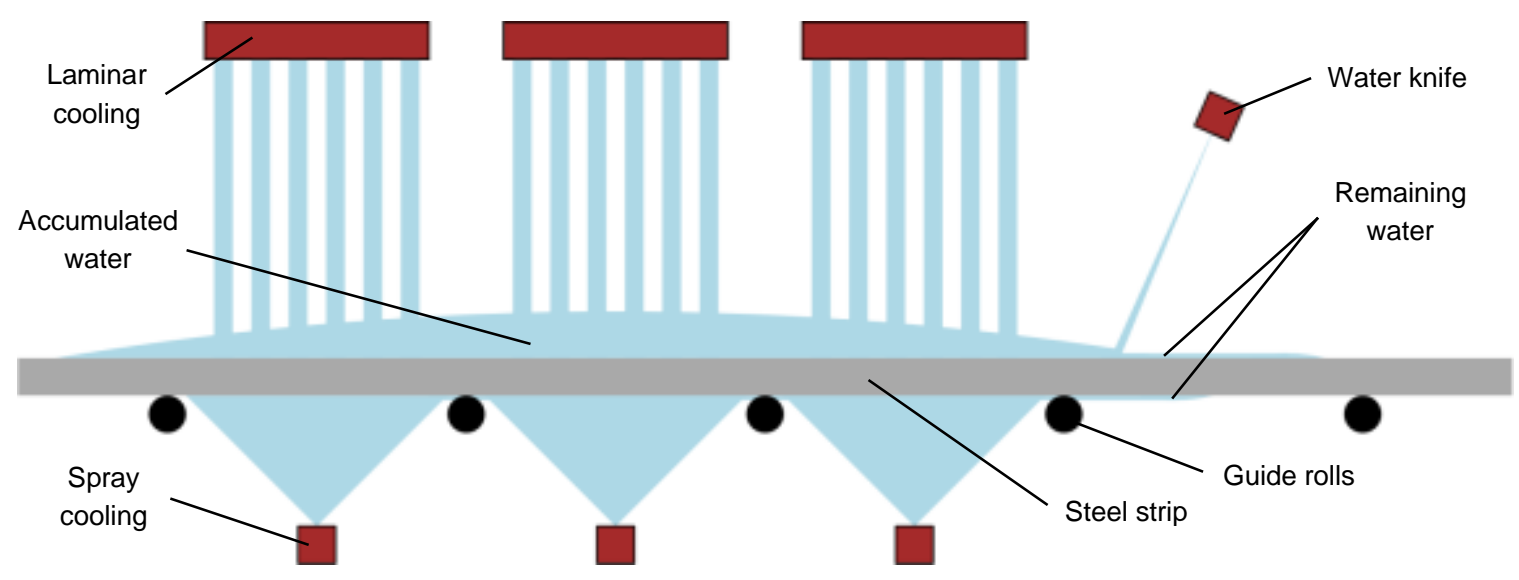

Figure 1 Remaining water during cooling

\section{EXPERIMENT DESCRIPTION AND EVALUATION}

The measurements of the heat transfer coefficient (HTC) during water cooling were done in Heat Transfer and Fluid Flow Laboratory on a laboratory test bench with linear movement of the test plate. The scheme of this test bench can be seen in Figure 2. The velocity during measurements performed in this study was $5 \mathrm{~m} / \mathrm{s}$. A test plate made from austenitic steel $(320 \times 300 \times 25 \mathrm{~mm})$ was used for all measurements. The test plate was equipped with $\mathrm{K}$-thermocouples located $0.8 \mathrm{~mm}$ under the cooled surface and attached to the carriage. Before each experiment, the test plate was placed in the electric heater and was heated to a temperature of $820^{\circ} \mathrm{C}$. After that, the test plate was placed in the upper position as shown in Figure $\mathbf{2}$ and the carriage with the test plate moved repeatedly under the nozzle at a velocity of $5 \mathrm{~m} / \mathrm{s}$ until the test plate temperature dropped to approx. $50{ }^{\circ} \mathrm{C}$. Temperature history and position information were recorded throughout the experiment and at the end of the experiment these data were downloaded to the computer.

The inverse computation was done to obtain the time dependent HTC and the time dependent surface temperature from the measured temperature history [14]. Based on the inverse computation and information about the position of the test plate, HTC can be evaluated as a function of test plate position and surface temperature (Figure 4). The position $1940 \mathrm{~mm}$ on the $\mathrm{x}$ axis in Figure 4 is the position directly under the nozzle. HTC as a function of position and surface temperature was used for analysis of the influence of the remaining water on cooling.

A full cone spray nozzle with the spray angle of $60^{\circ}$ was used. The flow rate was $0.56 \mathrm{l} / \mathrm{s}$ at $0.25 \mathrm{MPa}$ and 1.06 $\mathrm{l} / \mathrm{s}$ at $1 \mathrm{MPa}$. The spray distance was $500 \mathrm{~mm}$. 


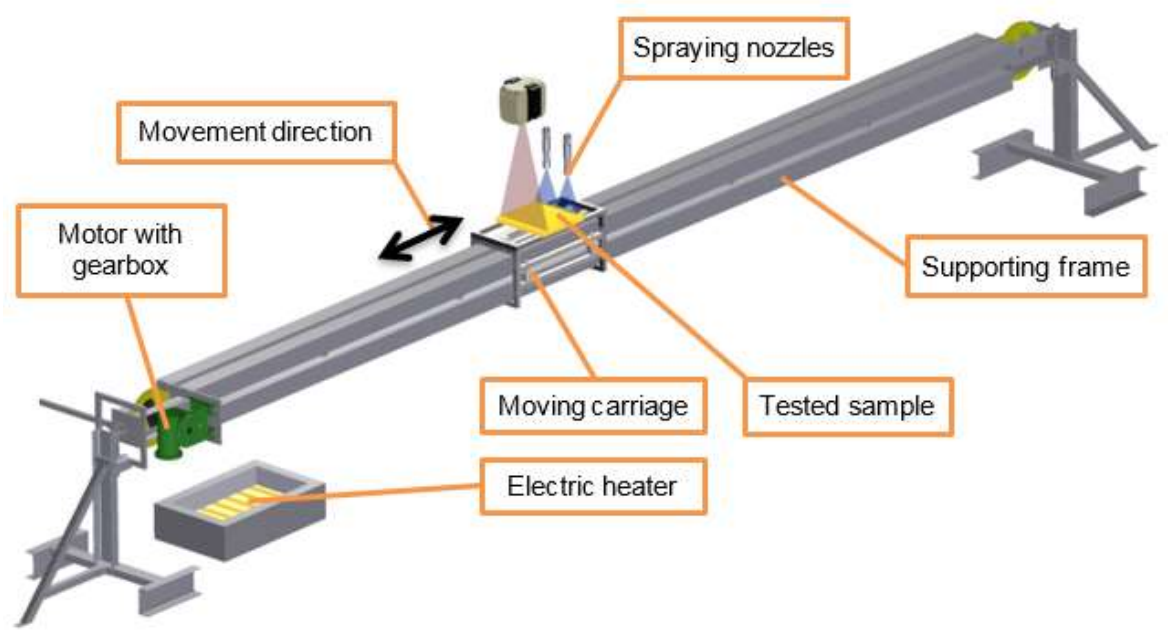

Figure 2 Experimental test bench for HTC measurements

Cooling was investigated in four different cooling areas as shown in Figure 3. Area "A" represents the situation where part of the test plate enters under the water spray, but the area where thermocouples are installed is still out of the direct impact of the water spray (position 1510-1659 mm). Area "B" is a zone where the thermocouples are directly under the water spray (position 1660-2219 mm). Area "C" is similar to area " $A$ ", but the difference is that the test plate leaves the water spray (position 2220-2369 mm). The last cooling area is area " $D$ ". The whole test plate is out of the water spray here (position 2370-5620 mm). The thermocouples were placed on the axis of the test plate (centre of the test plate in the direction of movement).

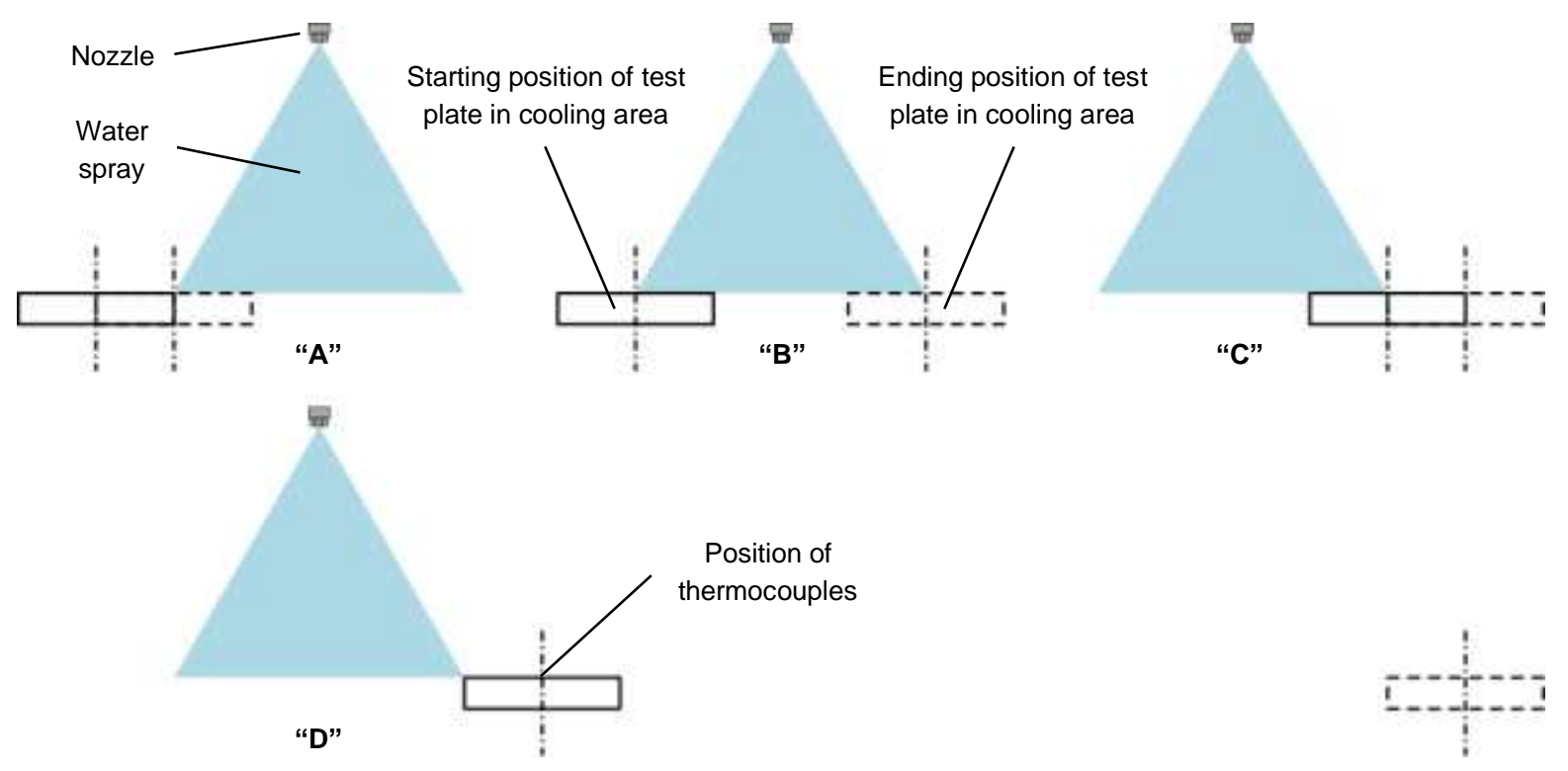

Figure 3 Investigated cooling areas

\section{RESULTS}

Two measurements were conducted at different flow rates - experiment $\mathrm{E} 1$ (flow rate $0.56 \mathrm{l} / \mathrm{s}$ at $0.25 \mathrm{MPa}$ ) and experiment E2 (flow rate $1.06 \mathrm{l} / \mathrm{s}$ at $1 \mathrm{MPa}$ ). The obtained $\mathrm{HTC}$ functions are shown as a function of test plate position and surface temperature in Figure 4. Data from the thermocouple located in the center of the test plate was used. 


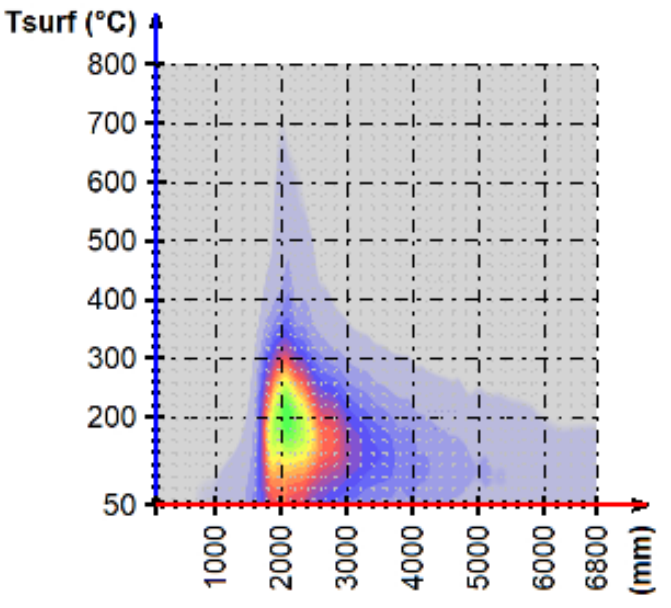

$\mathrm{HTC}\left(\mathrm{W} /\left(\mathrm{m}^{2} . \mathrm{K}\right)\right)$

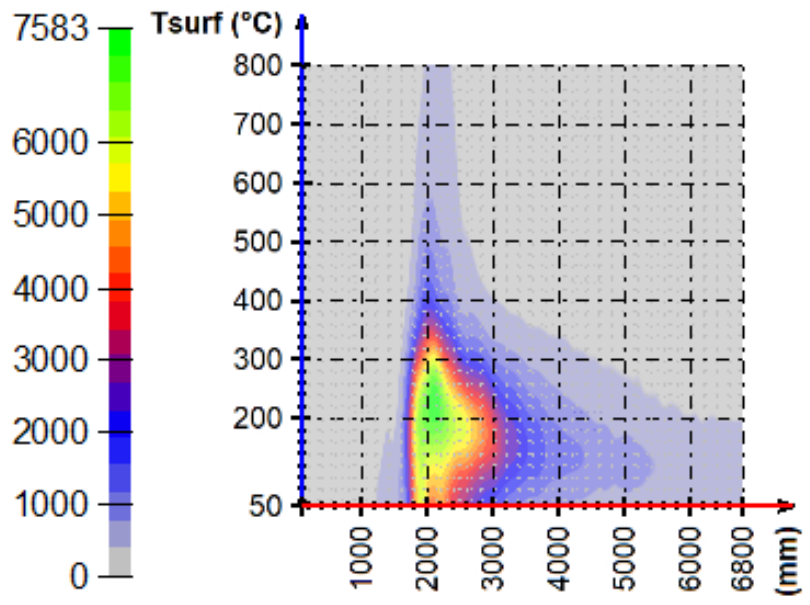

10437

$9000-$

8000

7000

6000

5000

4000

3000

2000

1000

$\mathrm{HTC}\left(\mathrm{W} /\left(\mathrm{m}^{2} . \mathrm{K}\right)\right)$

Figure $4 \mathrm{HTC}$ as a function of test plate position and surface temperature (left graph: experiment E1; right graph: experiment E2)

\subsection{Cooling in all areas}

The HTC and the heat flux are shown in Figure 5 as a function of position. This dependence can be obtained from Figure 4 for a specific surface temperature. In the case of Figure 5, the surface temperature was set to $150{ }^{\circ} \mathrm{C}$. The cooling areas "A"-"D" are shown in Figure 5 in the right graph. It can be seen that cooling is significant not only in area "B", where the test plate is directly under the water spray, but also in areas "C" and " $D$ ". In area " $D$ " there is no spraying water on the surface and heat transfer is realized only by evaporation of remaining water and radiation.
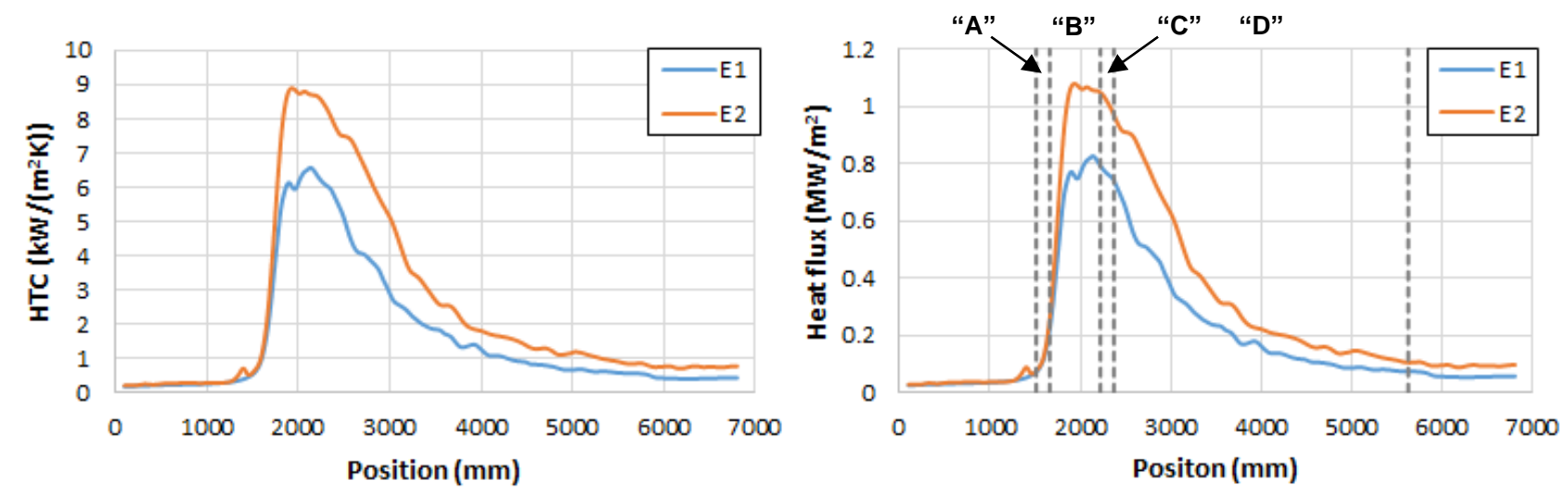

Figure $5 \mathrm{HTC}$ and heat flux dependent on the position for the surface temperature $150{ }^{\circ} \mathrm{C}$

The heat removed from the steel plate was calculated in each area for a surface temperature in the range of $50-800{ }^{\circ} \mathrm{C}$. The computed percentage share of the removed heat per unit time is shown in Figure 6 for each area "A"-" $D$ ". There is also information on how much heat is transferred to the surroundings by radiation. It is evident from Figure 4 that the effect of the remaining water becomes significant for surface temperatures below $500^{\circ} \mathrm{C}$ because HTC is also high in area "D" (above $2370 \mathrm{~mm}$ ). Also it can be seen that the biggest influence of the remaining water is for a surface temperature of around $150^{\circ} \mathrm{C}$ when intensive boiling occurs. Around this surface temperature, area "D" with the remaining water is responsible for almost $15 \%$ of the removed heat from steel per unit time (Figure 6). 

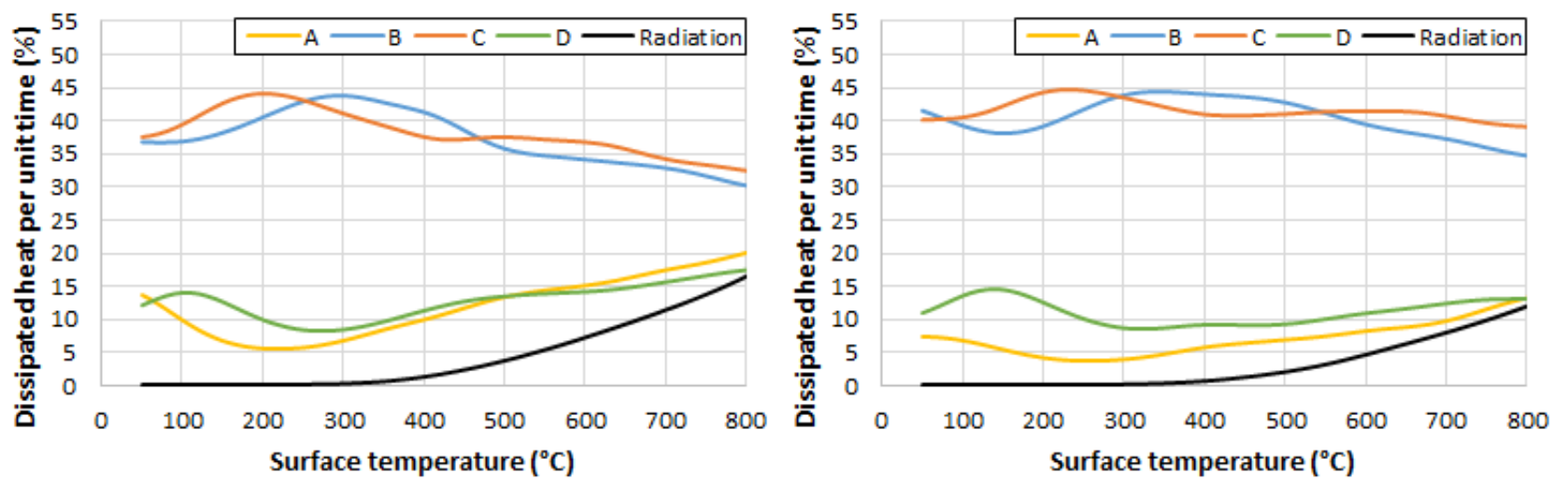

Figure 6 The percentage share of the removed heat per unit time in each cooling area and amount of heat transferred to the surroundings by radiation (left graph: experiment E1; right graph: experiment E2)

\subsection{Cooling in area " $D$ "}

The cooling in area " $\mathrm{D}$ " was investigated in more detail for a better understanding of the influence of the remaining water. The area was divided into four equally-sized sub-areas Q1, Q2, Q3 and Q4, where Q1 is the sub-area near the water cooling and Q4 is farthest from the water cooling. The average heat flux is shown in Figure 7 for each sub-area Q1-Q4 as a function of the surface temperature. The temperature dependence was obtained by averaging on the position interval (according to the specific sub-area).

It is evident from Figure 7 that cooling is mainly realized in the first half of area " $D$ ". The heat flux reaches a critical value for surface temperature at around $200^{\circ} \mathrm{C}$. The critical heat flux in Q1 is more than seven times higher than the critical heat flux in Q4. Also, it can be seen that in the case of the higher flow rate $(1.06 \mathrm{l} / \mathrm{s}$ at $1 \mathrm{MPa})$, the heat flux reaches higher values than for the flow rate $(0.56 \mathrm{l} / \mathrm{s}$ at $0.25 \mathrm{MPa})$ in all the sub-areas and the whole surface temperature range.
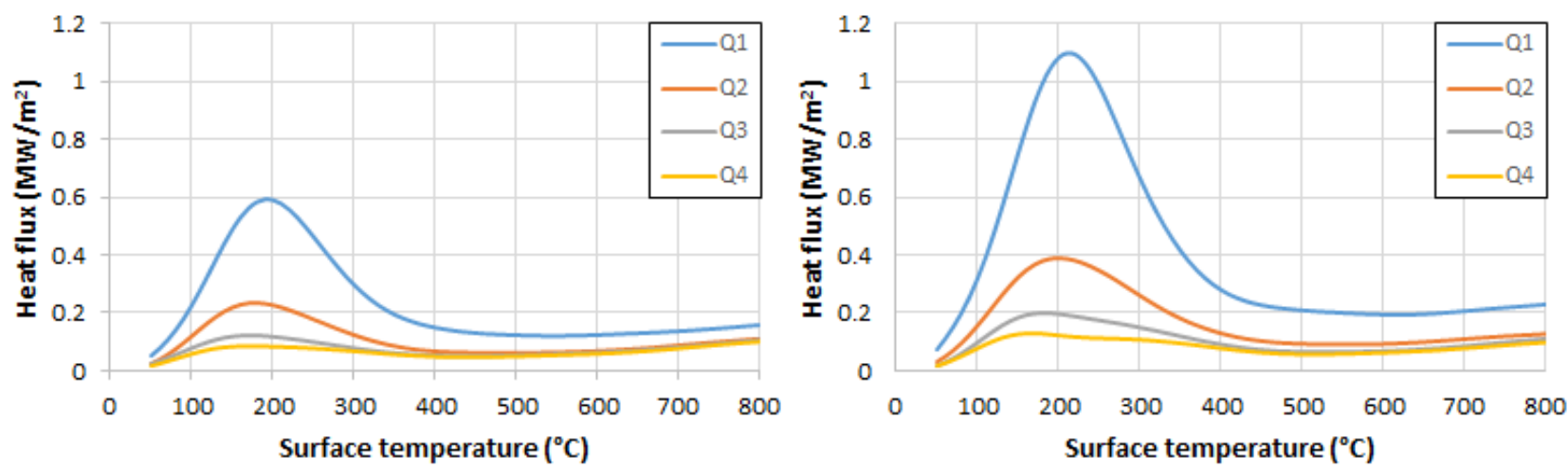

Figure 7 The average heat flux dependent on the surface temperature in sub-areas (Q1 - Q4) of cooling area "D" (left graph: experiment E1; right graph: experiment E2)

\section{CONCLUSION}

The influence of the remaining water on cooling was experimentally investigated. Two measurements were conducted with a full cone spray nozzle at different flow rates and the top cooling in different cooling areas (under the nozzle, transition areas, and outside the nozzle spray) was studied. It was found that cooling is significant not only in the area with water spray cooling, but also in the area behind the water cooling, where heat transfer is realized only by the remaining water and radiation. The cooling effect of the remaining water was most significant for a surface temperature of around $150{ }^{\circ} \mathrm{C}$. Almost $15 \%$ of heat was removed in the 
area with no direct water spray (area with remaining water only). It was also found that the influence of the remaining water was most significant right behind the water spray cooling. The critical heat flux in the first quarter of area "D" (area with only remaining water) was more than seven times higher than the critical heat flux in the last quarter. Furthermore, the heat flux is growing with the flow rate increase.

It was shown that the remaining water influences cooling and has to be considered when the surface temperature is below $500{ }^{\circ} \mathrm{C}$. Still, there is a lack of information about the behaviour of the remaining water and further research is needed to be done for a better understanding.

\section{ACKNOWLEDGEMENTS}

\section{The paper presented has been supported by the internal grant of the Brno University of Technology focused on specific research and development No. FSI-S-20-6478.}

\section{REFERENCES}

[1] CHEN, Shih-Jiun, TSENG, Ampere A. Spray and jet cooling in steel rolling. International Journal of Heat and Fluid Flow. 1992, vol. 13, no. 4, pp. 358-369.

[2] JONDHALE, K.V., WELLS, M.A., MILITZER, M., PRODANOVIC, V. Heat Transfer during Multiple Jet Impingement on the Top Surface of Hot Rolled Steel Strip. Steel research international. 2008, vol. 79, no. 12, pp. 938-946.

[3] JESCHAR, R., SPECHT, E., KÖHLER, Ch. Heat Transfer during Cooling of Heated Metals with Vaporizable Liquids. Quenching theory and technology. 2nd ed. Boca Raton: CRC Press Taylor \& Francis Group, 2010, pp. 159-178.

[4] GRADECK, M., KOUACHI, A., LEBOUCHÉ, M., VOLLE, F., MAILLET, D., BOREAN, J.L. Boiling curves in relation to quenching of a high temperature moving surface with liquid jet impingement. International Journal of Heat and Mass Transfer. 2009, vol. 52, no. 5-6, pp. 1094-1104.

[5] BROŽOVÁ, T., CHABIČOVSKÝ, M., HORSKÝ, J. Influence of the surface roughness on the cooling intensity during spray cooling. In: METAL 2016: 25rd International Conference on Metallurgy and Materials. Ostrava: TANGER, 2016, pp. 41-46.

[6] CHABIČOVSKÝ, M., HNÍZDIL, M., TSENG, A.A., RAUDENSKÝ, M. Effects of oxide layer on Leidenfrost temperature during spray cooling of steel at high temperatures. International Journal of Heat and Mass Transfer. 2015, vol. 88, pp. 236-246.

[7] KWON, Myeon Jae, PARK, II Seouk. Numerical Simulation of Cooling Process after Hot Rolling with Realistic Residual Water Levels. ISIJ International. 2015, vol. 55, no. 8, pp. 1791-1793.

[8] KWON, Myeon Jae, PARK, II Seouk. Hydrodynamic Investigation to Reflect Actual Residual Water Levels in Simulation of Strip Cooling after Hot Rolling. ISIJ International. 2014, vol. 54, no. 12, pp. 2936-2938.

[9] RESL, O., POHANKA, M. The Effect of Remaining Water Layer on Final Temperature of Steel Plate During Hot Rolling. In: METAL 2019: 28rd International Conference on Metallurgy and Materials. Ostrava: TANGER, 2019, pp. 355-360.

[10] XIE, Q., HUANG, Z., HOU, Q., ZHANG, L., CAI, J. Heat Transfer from a Hot Steel Plate Impinged by Air-atomized Water Jet and Impinging Water Jet. ISIJ International. 2019, vol. 59, no. 1, pp. 113-121.

[11] WU, W.-L., WANG, W.-C., LO, W. The study of improving the strip flatness in run-out-table during laminar cooling. The International Journal of Advanced Manufacturing Technology. 2018, vol. 95, no. 12, pp. 4419-4437.

[12] FUJIMOTO, H., SUZUKI, Y., HAMA, T., TAKUDA, H. Flow Characteristics of Circular Liquid Jet Impinging on a Moving Surface Covered with a Water Film. ISIJ International. 2011, vol. 51, no. 9, pp. 1497-1505.

[13] CHO, M.J., THOMAS, B.G., LEE, P.J. Three-Dimensional Numerical Study of Impinging Water Jets in Runout Table Cooling Processes. Metallurgical and Materials Transactions B. 2008, vol. 39, no. 4, pp. 593-602.

[14] POHANKA, M., KOTRBÁČEK, P. Design of cooling units for heat treatment. Heat treatment conventional and novel applications. Rijeka: InTech, 2012, pp. 1-20. 